\section{OPEN ACCESS}

Edited by:

Dobromir Dobrev,

University Duisburg-Essen, Germany

Reviewed by:

Rachel C. Myles,

University of Glasgow,

United Kingdom

Crystal M. Ripplinger,

University of California, Davis,

United States

$\mathrm{Na}$ Li,

Baylor College of Medicine, United States

${ }^{*}$ Correspondence: Shih-Lin Chang

ep.s/chang@msa.hinet.net

Shih-Ann Chen

epsachen@ms41.hinet.ne

Specialty section: This article was submitted to

Cardiac Rhythmology,

a section of the journal

Frontiers in Cardiovascular Medicine

Received: 30 October 2020

Accepted: 22 February 2021

Published: 16 March 2021

Citation:

Tsai Y-N, Hsiao Y-W, Lin S-F, Chan $Y-H$, Hsieh $Y-C$, Tang $W-H$, Lee A-S, Huang Y-T, Li H-Y, Chao T-F,

Higa S, Wu T-J, Chang S-L and Chen S-A (2021) Proinflammatory

Cytokine Modulates Intracellular

Calcium Handling and Enhances Ventricular Arrhythmia Susceptibility. Front. Cardiovasc. Med. 8:623510. doi: 10.3389/fcrm.2021.623510

\title{
Proinflammatory Cytokine Modulates Intracellular Calcium Handling and Enhances Ventricular Arrhythmia Susceptibility
}

\begin{abstract}
Yung-Nan Tsai ${ }^{1,2}$, Ya-Wen Hsiao ${ }^{2}$, Shien-Fong Lin ${ }^{3}$, Yi-Hsin Chan ${ }^{4}$, Yu-Cheng Hsieh ${ }^{1,5}$, Wei-Hua Tang ${ }^{2,6}$, An-Sheng Lee ${ }^{7}$, Yu-Ting Huang ${ }^{2}$, Hsing-Yuan Li ${ }^{8}$, Tze-Fan Chao ${ }^{2,9}$, Satoshi Higa ${ }^{10}$, Tsu-Juey Wu ${ }^{1,5}$, Shih-Lin Chang ${ }^{2,9 *}$ and Shih-Ann Chen ${ }^{1,2,5,9 *}$
\end{abstract}

${ }^{1}$ Institute of Clinical Medicine, National Yang-Ming University, Taipei, Taiwan, ${ }^{2}$ Division of Cardiology, Department of Medicine, Heart Rhythm Center, Taipei Veterans General Hospital, Taipei, Taiwan, ${ }^{3}$ Institute of Biomedical Engineering, National Chiao-Tung University, Hsin-Chu, Taiwan, ${ }^{4}$ Division of Cardiology, Chang Gung Memorial Hospital, Taoyuan, Taiwan, ${ }^{5}$ Department of Internal Medicine, Cardiovascular Center, Taichung Veterans General Hospital, Taichung, Taiwan, ${ }^{6}$ Division of Cardiology, Department of Internal Medicine, National Yang-Ming University Hospital, Yilan, Taiwan, ${ }^{7}$ Department of Medicine, Mackay Medical College, New Taipei, Taiwan, ${ }^{8}$ Division of Cardiology, Department of Pediatrics, Taipei Veterans General Hospital, Taipei, Taiwan, ${ }^{9}$ Faculty of Medicine, School of Medicine, National Yang-Ming University, Taipei, Taiwan, ${ }^{10}$ Cardiac Electrophysiology and Pacing Laboratory, Division of Cardiovascular Medicine, Makiminato Central Hospital, Urasoe, Japan

Background: The mechanism of Interleukin-17 (IL-17) induced ventricular arrhythmia (VA) remains unclear. This study aimed to investigate the effect of intracellular calcium $\left(\mathrm{Ca}_{\mathrm{i}}\right)$ handling and VA susceptibility by IL-17.

Methods: The electrophysiological properties of isolated perfused rabbit hearts under IL-17 (20 ng/ml, $N=6)$ and the IL-17 with neutralizer $(0.4 \mu \mathrm{g} / \mathrm{ml}, N=6)$ were evaluated using an optical mapping system. The action potential duration (APD) and $\mathrm{Ca}_{\mathrm{i}}$ transient duration ( $\left.\mathrm{Ca}_{i} \mathrm{TD}\right)$ were examined, and semiquantitative reverse transcriptase-polymerase chain reaction analysis of ion channels was performed.

Results: There were longer $\mathrm{APD}_{80}, \mathrm{Ca}_{\mathrm{i}} \mathrm{TD}_{80}$ and increased thresholds of $\mathrm{APD}$ and $\mathrm{Ca}_{\mathrm{i}} \mathrm{TD}$ alternans, the maximum slope of APD restitution and induction of VA threshold in IL-17 group compared with those in IL-17 neutralizer and baseline groups. During ventricular fibrillation, the number of phase singularities and dominant frequency were both significantly greater in IL-17 group than in baseline group. The mRNA expressions of the $\mathrm{Na}^{+} / \mathrm{Ca}^{2+}$ exchanger, phospholamban, and ryanodine receptor $\mathrm{Ca}^{2+}$ release channel were upregulated, and the subunit of L-type $\mathrm{Ca}^{2+}$ current and sarcoplasmic reticulum $\mathrm{Ca}^{2+}$-ATPase $2 \mathrm{a}$ were significantly reduced in $\mathrm{IL}-17$ group compared to baseline and IL-17 neutralizer group.

Conclusions: IL-17 enhanced $\mathrm{Ca}_{\mathrm{i}} \mathrm{TD}$ and APD alternans through disturbances in calcium handling, which may increase VA susceptibility.

Keywords: alternans, the maximum calcium transient, IL-17 neutralizer, IL-17, ventricular arrhythmias 


\section{INTRODUCTION}

Ischemic ventricular arrhythmia (VA) is strongly associated with increased inflammatory activities (1). Although interleukin (IL)17 , the pro-inflammatory cytokine of the newly described $\mathrm{T}$ helper $17\left(T_{H} 17\right)$ cell subset, has a major function in shielding the host anti extracellular pathogens, it promotes inflammation in autoimmune diseases and mediator of tissue inflammation $(2,3)$. Former studies have demonstrated that downregulated IL17 expression inhibits the inflammatory response and improves heart function (4). On the other hand, an important role for IL17 in post-myocarditis cardiac remodeling and the development to dilated cardiomyopathy was described (5). Our previous study showed that IL-17 treatment lead to fibrosis, collagen production, and apoptosis in the left ventricular (LV) tissue. Moreover, the study showed that increased IL-17 activates mitogen-activated protein kinase (MAPK) and thereby increases the expression of downstream target genes, including IL-6, tumor necrosis factor (TNF), C-C motif chemokine ligand 20 (CCL20), and C-X-C motif chemokine ligand 1 (CXCL1) (4). VA can be triggered through multiple electrophysiological mechanisms, including prolonged ventricular action potential duration (APD), slowed conduction, increased electrical restitution, and perturbed intracellular calcium $\left(\mathrm{Ca}_{\mathrm{i}}\right)$ signaling $(6,7)$. Therefore, inflammation and $\mathrm{Ca}_{\mathrm{i}}$ handling are involved in VA. However, the function of IL-17 with regard to $\mathrm{Ca}_{i}$ alternans and VA susceptibility are yet unclear. Therefore, this study aimed to investigate the influence of IL-17 on $\mathrm{Ca}_{\mathrm{i}}$ handling and VA susceptibility.

\section{MATERIALS AND METHODS}

\section{Surgical Preparation}

The study protocol was reviewed and approved by the Institutional Animal Care and Use Committee of Taipei Veterans General Hospital. New Zealand white male rabbits $(N=30)$, weighing $2.5-3.5 \mathrm{~kg}$, were used for optical mapping ( $N=$ 12 ) and extraction of RNA $(N=18)$. Rabbits were deeply anesthetized using intramuscular injection of a mixture of Zoletil $50(10 \mathrm{mg} / \mathrm{kg})$ and Xylazine $(5 \mathrm{mg} / \mathrm{kg})$. The subcutaneously at the incision site, we injected $2 \%$ Xylocaine $(3 \mathrm{~mL})$. An intravenous bolus of heparin (2,500 units) was administered to the rabbits to avoid intracardiac clot formation. The hearts of the experimental rabbits were exposed by median thoracotomy and pericardiotomy, and the rabbits were quickly sacrificed by manual excision of the beating hearts, which were directly submerged in cold with oxygenated Tyrode's solution of the following composition $(\mathrm{mmol} / \mathrm{L}): \mathrm{Na}^{+}, 156.5 ; \mathrm{K}^{+}, 4.7 ; \mathrm{Ca}^{2+}$, $1.5 ; \mathrm{H}_{2} \mathrm{PO}_{4}^{-}, 0.5 ; \mathrm{Cl}^{-}, 137 ; \mathrm{HCO}_{3}^{-}, 28$; glucose, 20 with a $\mathrm{pH}$ of 7.40 (4).

\section{Langendorff Preparation and Optical Mapping}

The hearts were suspended on the cannula with silk tied through the ascending aorta. Deep insertion of the aorta into the perfusion cannula must be avoided because it can cause the compression of the coronary arteries. Continuous circulation and heart perfusion were preserved using a roller pump. The perfusion oxygenated Tyrode's solution flowed through the coronary arteries and returned through the coronary sinus was collected in a reservoir (thermostatically maintained at $37^{\circ} \mathrm{C}$ ), from which the perfusion solution returned to the circulation system. The system was regulated to keep a constant perfusion pressure (30$60 \mathrm{mmHg}$ under controlled conditions). Myocardial pseudoelectrocardiogram (pseudo-ECG) signals were monitored using 3 pseudo-ECG pins that were inserted into the ventricles. A mapping catheter was inserted and secured inside the right ventricular (RV) apex through pulmonary vein and RV. Using a camera optical mapping system, the epicardial activation patterns were studied during ventricular pacing $(4,6)$. The hearts were stained with RH237 $(10 \mu \mathrm{mol} / \mathrm{L}, 0.4 \mu \mathrm{mol}$ in $40 \mathrm{ml}$ Tyrode's solution, from Invitrogen, Grand Island, NY) for membrane potential $(\mathrm{Vm})$ mapping and with Rhod-2 AM $(1.2 \mu \mathrm{mol} / \mathrm{L}, 0.18 \mu \mathrm{mol}$ in Tyrode's solution, from Invitrogen, Grand Island, NY) for $\mathrm{Ca}_{\mathrm{i}}$ mapping. Blebbistatin (15-20 $\mu \mathrm{mol} / \mathrm{L}$, from Tocris Bioscience, Minneapolis, MN) was used to inhibit cardiac contraction. We used cytochalasin-D $(5 \mu \mathrm{mol} / \mathrm{L})$, an excitation-contraction uncoupler to minimize motion artifacts. The hearts were excited using 2 light-emitting diode modules at a wavelength of $532 \mathrm{~nm}$. The signals were recorded simultaneously using 2 MiCAM02 cameras (BrainVision, Tokyo, Japan). Optical signals were gathered at $2 \mathrm{~ms} /$ frame temporal resolution, acquired from $128 \times 128$ sites simultaneously over a $30 \times$ $30 \mathrm{~mm}^{2}$ area in each aspect of those hearts. For each optical recording, data were acquired continuously for $2 \mathrm{~s}$. Optical signals were processed with both spatial $(3 \times 3$ pixels Gaussian filter) and temporal (3 frames moving average) filtering $(7,8)$.

\section{The Rationale for IL-17 and IL-17 Neutralizer Dosage}

In our previous studies, IL-17 concentration $(200 \mathrm{pg} / \mathrm{ml})$ was measured from heart failure (HF) rabbit serum (4). To mimic the inflammatory process of HF, we used the dosage of IL-17 ranged from $20 \mathrm{ng} / \mathrm{ml}$ in Langendorff perfusion which is similar to the level of IL-17 in whole rabbit. Neutralizing antibody $0.4 \mu \mathrm{g} / \mathrm{ml}$ was used for block of IL-17 receptor before IL-17 reperfusion (4). In addition, previous studies showed that IL-17 produced rapid phosphorylation of protein kinase B and ERK within 5 min, and it rapidly enhanced excitability (9). Therefore, IL-17 with dosage of $20 \mathrm{ng} / \mathrm{ml}$ would be adequate to study the influences of IL-17 on VA in Langendorff perfusion study, and dosage of $0.4 \mu \mathrm{g} / \mathrm{ml}$ in neutralizing antibody would be adequate to be an antidote. IL-17 neutralizer is a recombinant, high affinity, fully human $\operatorname{IgG} 1 / \kappa$ monoclonal antibody that selectively binds to and neutralizes IL-17. Binding of IL-17 by IL-17 neutralizer inhibits its interaction with the IL-17 receptor, thereby inhibiting the release of other proinflammatory cytokines, chemokines and mediators of tissue damage and reducing the contribution of IL-17 to these inflammatory diseases (10).

\section{Experimental Protocol and Electrophysiological Study}

IL-17 (20 ng/mL, RPA063Rb01; Cloud-Clone Corp) was added and perfused for $10 \mathrm{~min}$ in the Langendorff-perfused normal rabbit heart $(N=6)$. For neutralizing experiments $(N=$ 6), IL-17 neutralizing antibodies $(0.4 \mu \mathrm{g} / \mathrm{mL}$, eBio64CAP17; 
eBioscience) were perfused for $10 \mathrm{~min}$ before the perfusion of IL-17 $20 \mathrm{ng} / \mathrm{mL}$ for $10 \mathrm{~min}$. There was no washout phase. The baseline group was normal rabbit heart before treatment. A bipolar electrode was inserted into the RV apex for pacing. This protocol comprised different pacing cycle lengths (PCL) ranging from 500 to $130 \mathrm{~ms}$. Regarding each PCL, the S1 pacing train was obtained during steady-state S1 pacing ( $>50$ beats after the onset of pacing), and then optical mapping data was recorded. $\mathrm{APD}_{80}$ and $\mathrm{Ca}_{\mathrm{i}}$ transient duration $\left(\mathrm{Ca}_{\mathrm{i}} \mathrm{TD}_{80}\right)$ were measured at $80 \%$ repolarization which would avoid the undetermined baseline in phase 4 period $(4,6,7)$. The $\mathrm{F} / \mathrm{F}_{0}$ ratio was used to measure the relative concentration of $\mathrm{Ca}_{\mathrm{i}}$, and the maximum Cai transient $\mathrm{F} / \mathrm{F}_{0}$ were measured (6).

\section{APD and $\mathrm{Ca}_{\mathrm{i}}$ Alternans During S1 Pacing}

Rapid pacing protocol was performed, initially at cycle length of $500 \mathrm{~ms}$, decremented by $50 \mathrm{~ms}$ every 8 beats until reaching a cycle length of 250 and $250 \mathrm{~ms}$ decremented by $10 \mathrm{~ms}$ until reaching a cycle length of $130 \mathrm{~ms}$ or the loss of 1:1 capture of the ventricles. The thresholds of $\mathrm{APD}$ and $\mathrm{Ca}_{\mathrm{i}}$ alternans were defined by determining differences in local APD and $\mathrm{Ca}_{\mathrm{i}}$ on consecutive beats (11).

\section{Induction of Ventricular Arrhythmia and Phase Mapping}

We used Fast Fourier Transforms of pseudo-ECG (4 $\mathrm{s}$ in duration) to determine the dominant frequency (DF) of ventricular fibrillation (VF) at IL-17 and IL-17 neutralizer group. Phase mapping was performed to assess the location and development of phase singularities (PSs). PS observed on the phase maps was defined as a site with an ambiguous phase enclosed by pixels showing a continuous phase progression from $-\pi$ to $+\pi$. Previous studies recommend that PSs are a robust alternative representation of wavebreaks (7), which serve as the source of VF. To quantify wavebreaks during VF, the numbers of PSs in the phase map were calculated manually every 10 frames for 1,000 frames in each episode of VF (7). VA inducibility was measured using eight-beat drive trains at 240-and 200-ms BCLs, followed by 1-3 ventricular extrastimuli. Single (S2), double (S2$\mathrm{S} 3)$, or triple (S2-S3-S4) premature stimuli were applied with a coupling interval of $160 \mathrm{~ms}$ (S2), $150 \mathrm{~ms}$ (S3), or $140 \mathrm{~ms}$ (S4), and gradually shortened in 5-ms steps until VA was induced or until the ventricular effective refractory period was reached. VA included VF, and tachycardia was defined as $\geq 4$ consecutive ventricular ectopic beats at a cycle length $\leq 150 \mathrm{~ms}$ (ventricular tachycardia) or by unidentifiable and low-voltage QRS complexes (VF). The percentage of inducible VA episodes was counted as the ratio of induced VA episodes to the number of ventricular extra stimuli applied. This induction protocol was standardized across all experiments (4).

\section{Semiquantitative Reverse Transcription Polymerase Chain Reaction}

Tissues were obtained from Langendorff perfusion normal group $(N=6)$, IL-17 neutralizer group $(N=6)$, and IL-17 group $(N=6)$. In IL-17 group, IL-17 $20 \mathrm{ng} / \mathrm{mL}$ was perfused for $10 \mathrm{~min}$. In IL-17 neutralizer group, IL-17 neutralizing antibodies
$0.4 \mu \mathrm{g} / \mathrm{mL}$ was perfused for $10 \mathrm{~min}$ following the perfusion of IL-17 $20 \mathrm{ng} / \mathrm{mL}$ for $10 \mathrm{~min}$. The LV tissues using the RNeasy ${ }^{\circledR}$ Fibrous Tissue Kit (Qiagen, Valencia, CA, USA), according to the manufacturer's protocol. Further, cDNA was synthesized using Prime Script ${ }^{\mathrm{TM}}$ Reverse Transcriptase (Takara Bio Inc., Kyoto, Japan) with a random hexamer from $5.0 \mu \mathrm{g}$ of total RNA. The resulting cDNA was detected by polymerase chain reaction (PCR) via the DreamTaq Green PCR Master Mix (Thermo Scientific Inc., Waltham, MA, USA) for 40 cycles at an annealing temperature of $55^{\circ} \mathrm{C}$ with a Veriti ${ }^{\circledR}$ 96-Well Fast Thermal Cycler (Applied Biosystems, Carlsbad, CA, USA). PCR products were visualized under UV light with ethidium bromide and quantified with Image-Pro Plus software. Primer sequences for PCR detection are provided in Supplementary Table 1.

\section{Data Analysis}

APD was measured from the steepest deflection of the slope of phase 0 to the time of $A P D_{80}$. We used the SD of $A P D_{80}$ at all mapped pixels to measure the spatial heterogeneity of APD (7). Conduction velocity $(\mathrm{CV})$ in squares $(10 \times 10 \mathrm{~mm})$ located at the centers of the anterior aspects of LV was measured (4). The diastolic interval (DI) was measured from the $\mathrm{APD}_{80}$ of the prior beat to the current action potential onset. A restitution curve (RC) was plotted using $\mathrm{APD}_{80}$ against the preceding DI by $\mathrm{S} 1$ pacing $(4,6,7)$. The maximum slope of RC was counted by firstorder exponential fitting using ORIGIN software (Microcal) (12). The time constant of the $\mathrm{Ca}_{\mathrm{i}}$ decay (tau value) was determined by a monoexponential least-squares fit. The detected longest S1 PCL threshold was spatially concordant alternans (SDA) threshold was defined (13). Positive coupling of $\mathrm{Ca}_{\mathrm{i}}-\mathrm{Vm}$ alternans was defined as long APD corresponds to large $\mathrm{Ca}_{\mathrm{i}}$ transient and negative coupling of $\mathrm{Ca}_{\mathrm{i}}-\mathrm{Vm}$ alternans was defined as long APD corresponds to small $\mathrm{Ca}_{\mathrm{i}}$ transient. The incidence of positive and negative coupling episodes was counted as the ratio of positive or negative coupling episodes of $\mathrm{Ca}_{\mathrm{i}}-\mathrm{Vm}$ alternans to the number of pacing numbers applied (14).

\section{Statistical Analyses}

Quantitative data were expressed as mean \pm SD. Two-way repeated measures analysis of variance was used to compare the differences before and after IL-17 group in subgroups. A senior biostatistician performed the statistical analysis using SPSS version 17 (SPSS Institute Inc., Chicago, IL, USA). Furthermore, $p<0.05$ was considered to be statistically significant.

\section{RESULTS}

\section{Effect of IL-17 on $\mathrm{Ca}_{\mathrm{i}}$ Transient and APD/Ca $a_{i}$ TD Prolongation}

Optical images were captured from the whole ventricle. The maximum $\mathrm{Ca}^{2+} \mathrm{F} / \mathrm{F}_{0}$ was recorded in $\mathrm{LV}$ during ventricular pacing at $300 \mathrm{~ms}$ PCL (Figure 1A). The maximum $\mathrm{Ca}^{2+} \mathrm{F} / \mathrm{F}_{0}$ was significantly reduced in the IL-17 group compared with the baseline and IL-17 neutralizer groups (1.01 $\pm 0.003,1.04$ $\pm 0.008,1.03 \pm 0.007$, respectively; $P<0.001$ ) (Figure 1B). No significant difference in maximum $\mathrm{Ca}^{2+} \mathrm{F} / \mathrm{F}_{0}$ was observed between the baseline and IL-17 neutralizer groups $(P=0.06)$. 
Thai et al.

Proinflammation Enhances Ventricular Arrhythmia

A

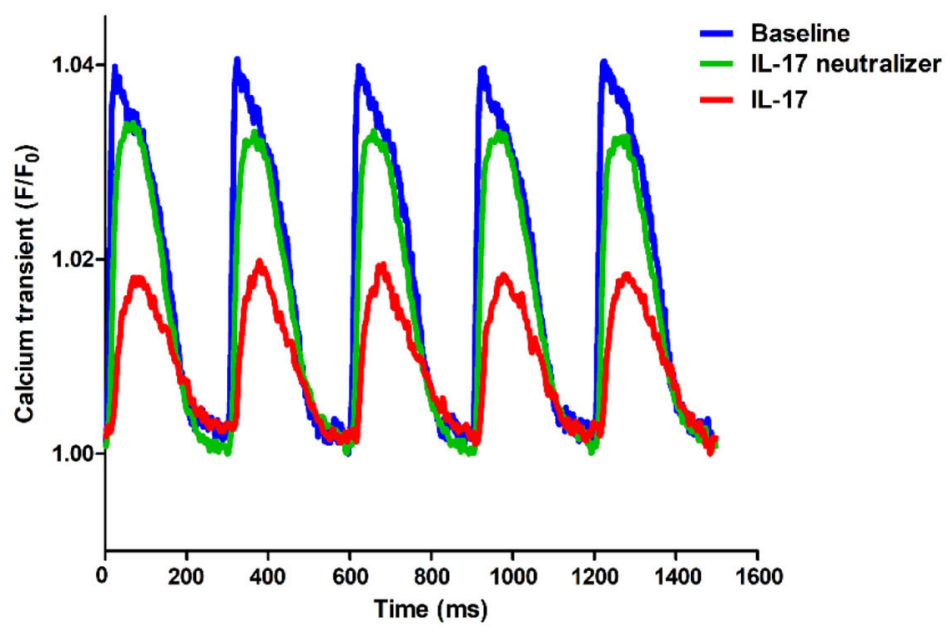

B

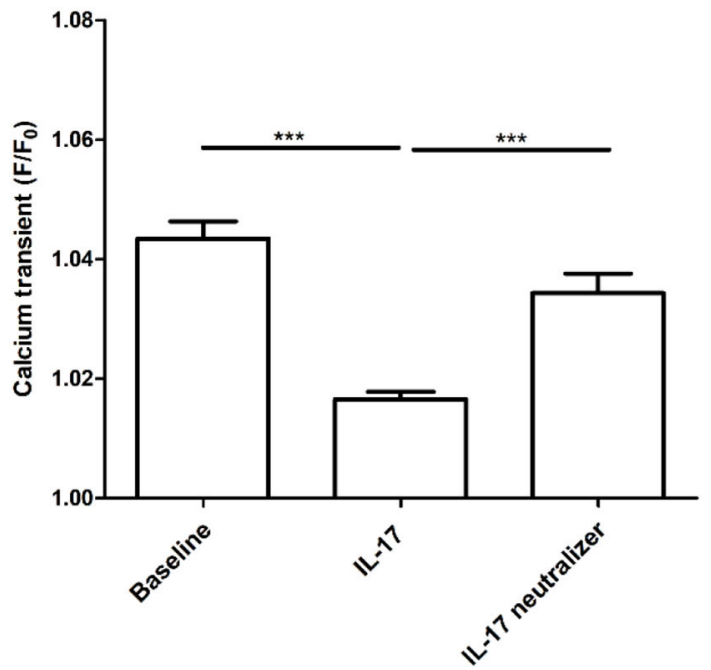

C

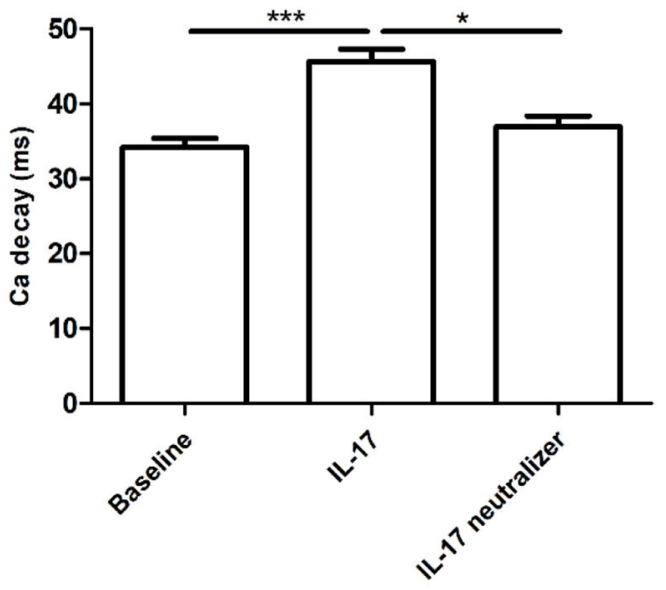

FIGURE 1 | Effect of IL-17 infusion, IL -17 neutralizer infusion alone, and baseline on intracellular calcium transient. The maximum Ca ${ }^{2+}$ transient (F/F F $_{\text {ins }}$ decreased after IL-17 infusion compared with baseline $\mathbf{( A , B )}$. Cai decay (tau value) was prolonged in the IL-17 group than that in the baseline and IL-17 neutralizer groups $(\mathbf{C}) .{ }^{*} P$ $<0.05 ;{ }^{* \star} P<0.001 . \mathrm{Ca}_{\mathrm{i}}$, intracellular calcium.

Frontiers in Cardiovascular Medicine | www.frontiersin.org

4

March 2021 | Volume 8 | Article 623510 
Thai et al.

Proinflammation Enhances Ventricular Arrhythmia

A
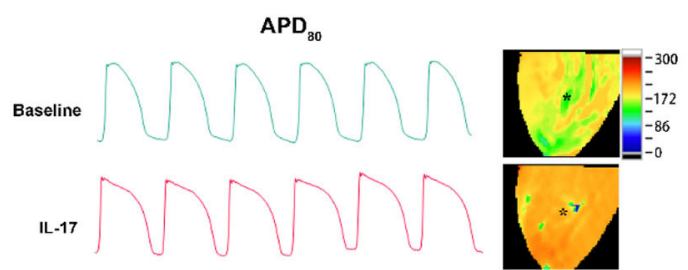

IL -17 neutralizer

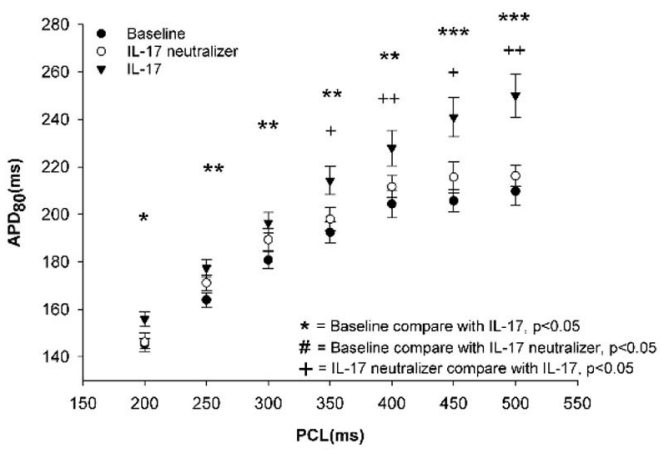

C

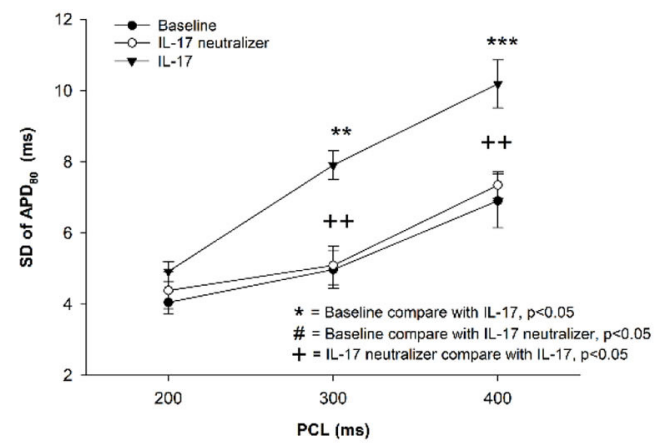

E

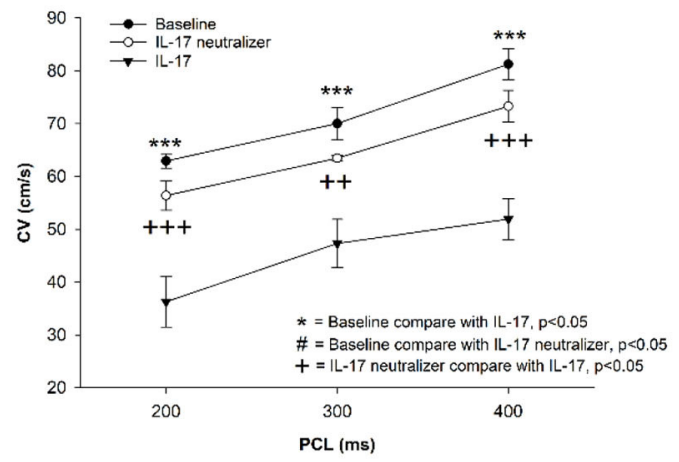

B

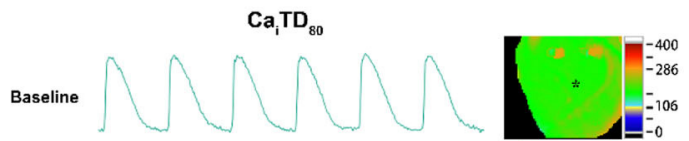

IL-17 neutralizer

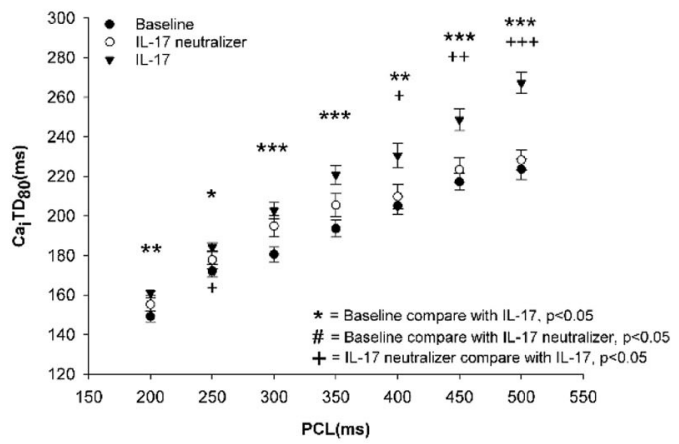

D

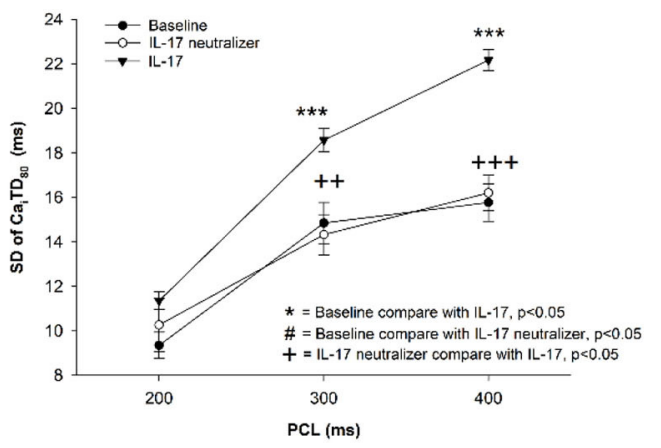

FIGURE 2 | Effect of IL-17 on spatial heterogeneity of APD and $\mathrm{Ca}_{\mathrm{i}} \mathrm{TD}$ in the baseline and IL-17 neutralizer groups. APD $\mathrm{D}_{80}$ and $\mathrm{Ca}_{\mathrm{i}} \mathrm{TD}_{80}$ (A,B). SD of APD 80 and SD of $\mathrm{Ca}_{\mathrm{i}} \mathrm{TD}_{80}$ (C,D). CV (E) in the LV during different POLs. ${ }^{\star} P<0.05 ;{ }^{* \star} P<0.01 ;{ }^{\star \star \star} P<0.001 ;{ }^{+} P<0.05 ;{ }^{++} P<0.01 ;{ }^{+++} P<0.001$. APD, action potential duration; $\mathrm{Ca}_{\mathrm{i}} \mathrm{TD}$, calcium transient duration; $\mathrm{APD}_{80}$, action potential duration at repolarizations of $80 \%$; $\mathrm{Ca}_{\mathrm{i}} \mathrm{TD}_{80}$, calcium transient duration at repolarizations of $80 \%$; $\mathrm{CV}$, conduction velocity; PCL, pacing cycle length; LV, left ventricle.

Frontiers in Cardiovascular Medicine | www.frontiersin.org

5

March 2021 | Volume 8 | Article 623510 
Thai et al.

Proinflammation Enhances Ventricular Arrhythmia

A

PCL(ms) Baseline

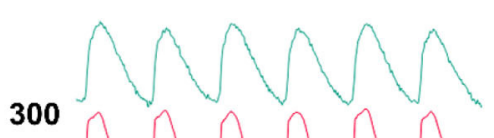

300

250
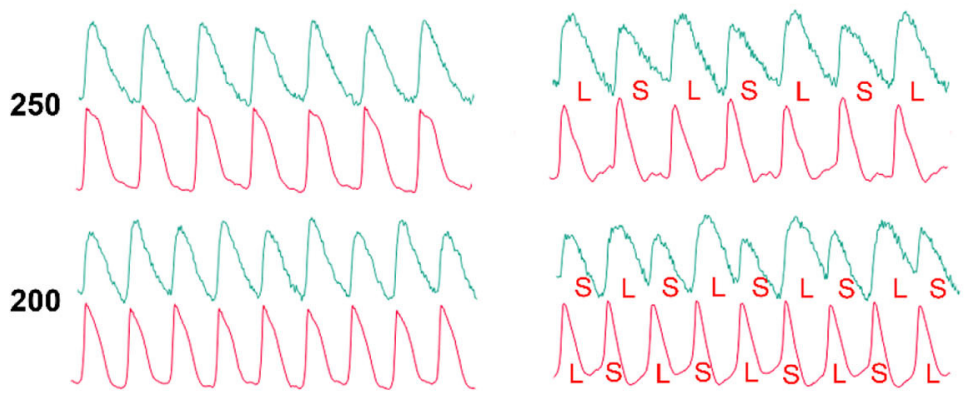

180

160
IL-17
IL-17 neutralizer

$m$ mm m m nun n Non N

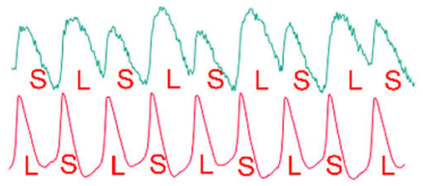

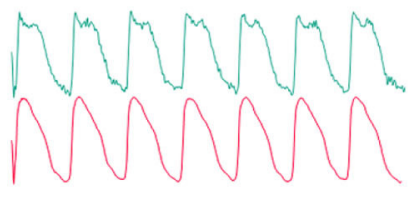

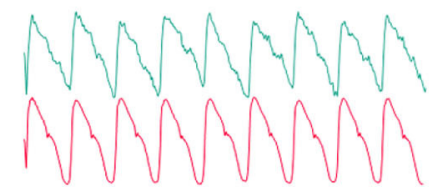

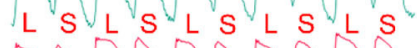

LS LS LS LS S
B

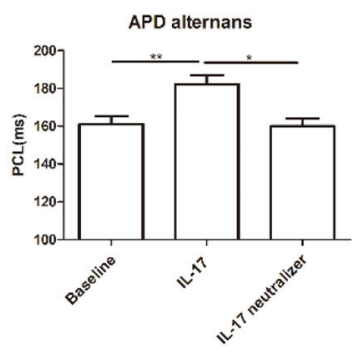

D

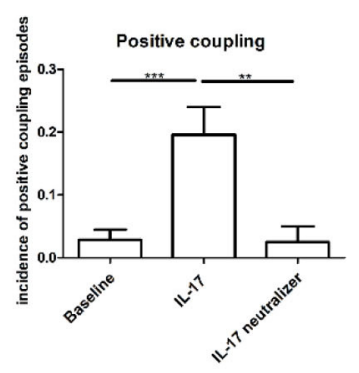

C
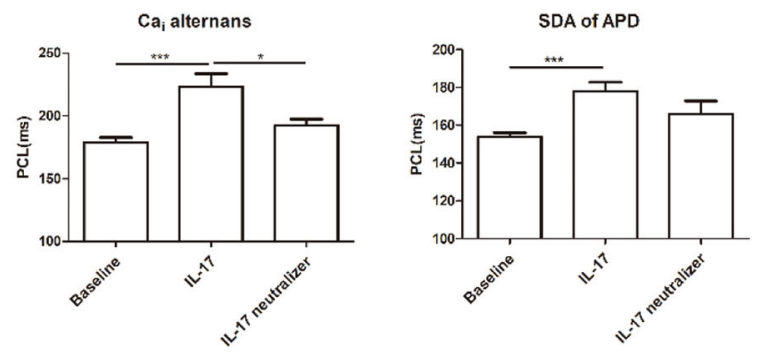

E
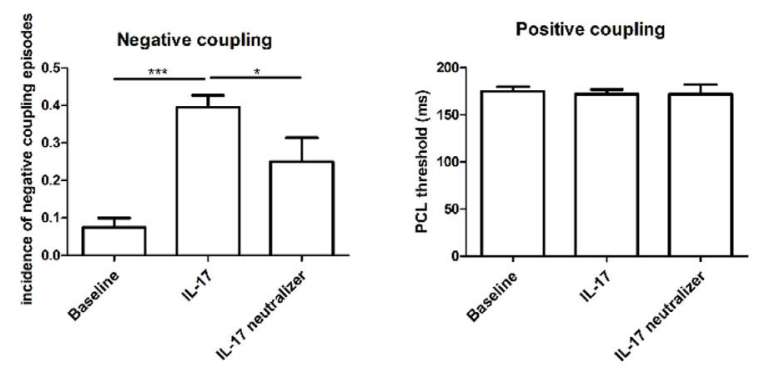

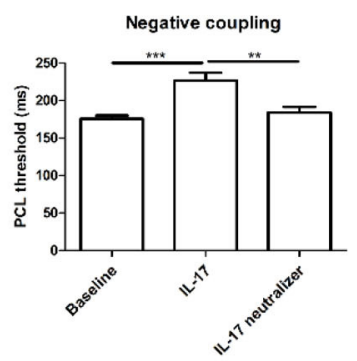

FIGURE 3 | Effects of PCL on APD and $\mathrm{Ca}_{i} \mathrm{TD}$ alternans. (A) The green and red tracings indicated the $\mathrm{Ca}_{i}$ and Wm signals, respectively. L, long; S, short. (B) APD and $\mathrm{Ca}_{i}$ alternans. (C) SDA of APD and $\mathrm{Ca}_{i}$. (D) Incidence of positive and negative coupling of $\mathrm{Ca}_{\mathrm{i}}-\mathrm{Vm}$ alternans. (E) PCL threshold of positive and negative coupling of $\mathrm{Ca}_{\mathrm{i}}-\mathrm{Vm}$ alternans. ${ }^{\star} P<0.05 ;{ }^{\star \star} P<0.01 ;{ }^{\star \star \star} P<0.001$. Wm, voltage-driven membrane; SDA, spatially discordant alternans, and other abbreviations as in Figures $\mathbf{1}, \mathbf{2}$.

Frontiers in Cardiovascular Medicine | www.frontiersin.org

6

March 2021 | Volume 8 | Article 623510 
A

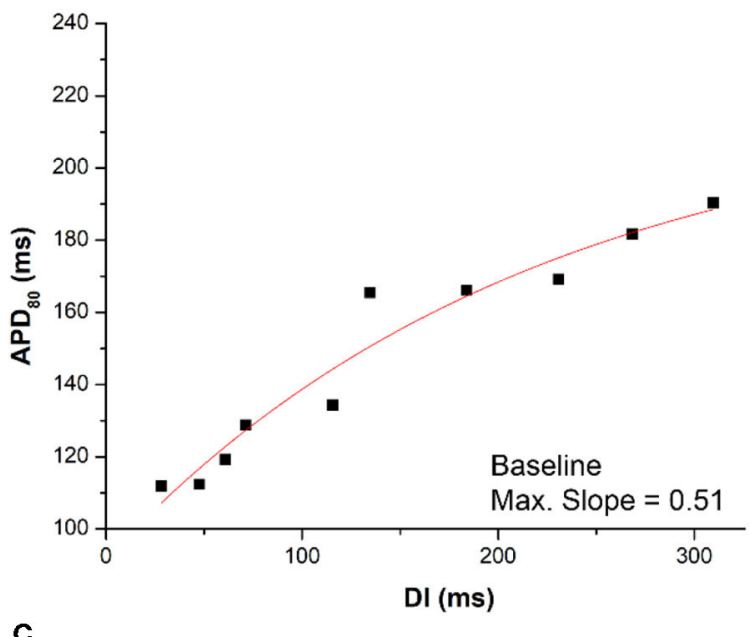

C

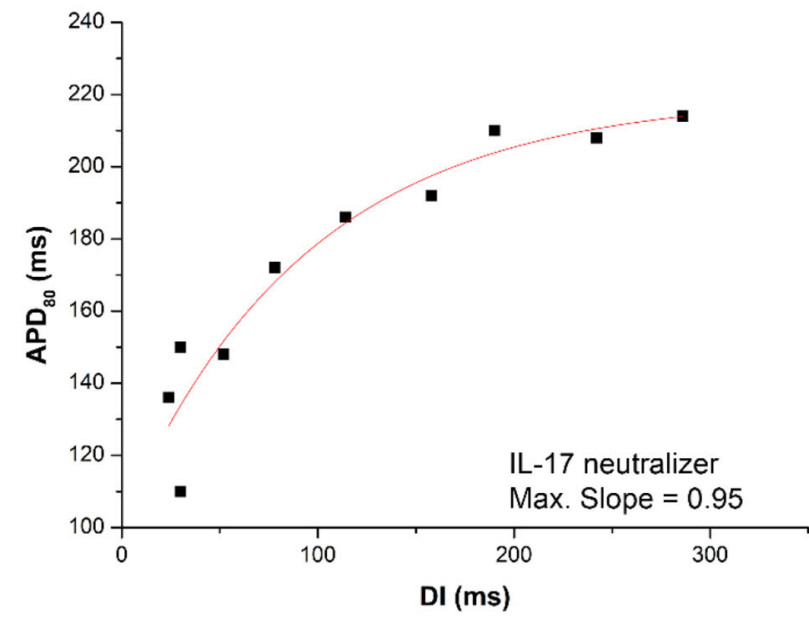

E

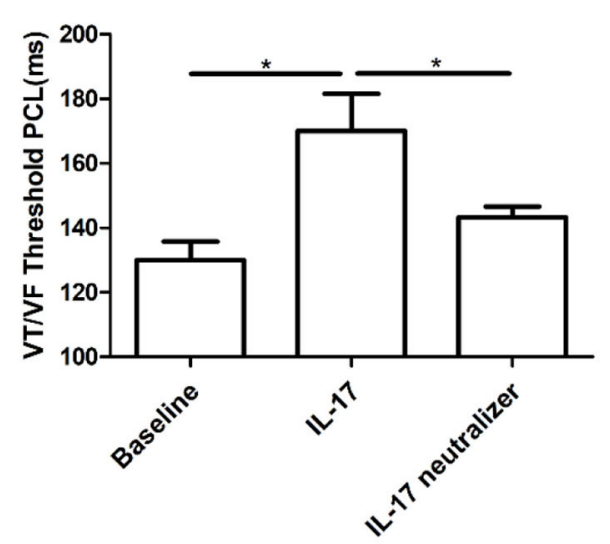

B

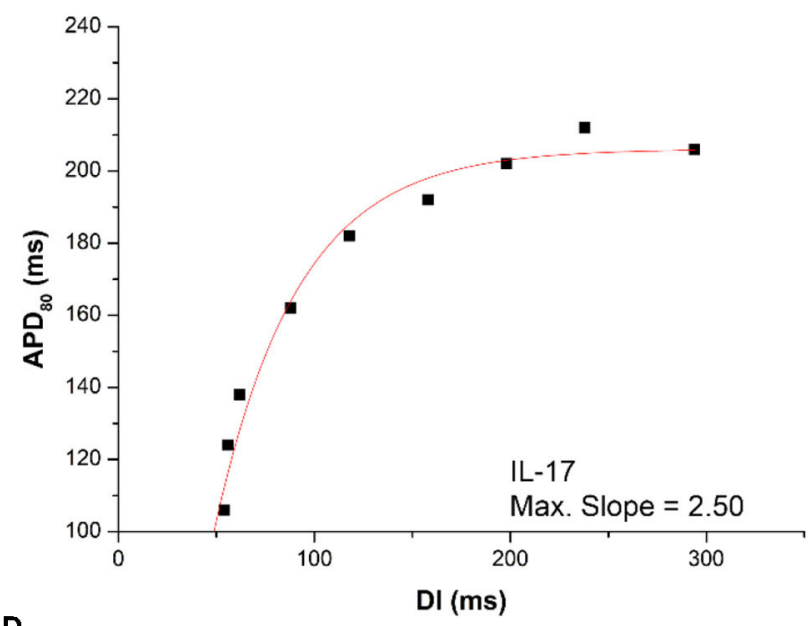

D

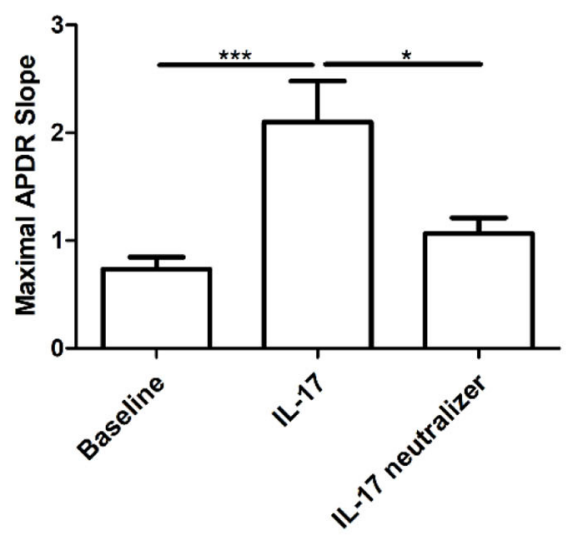

F

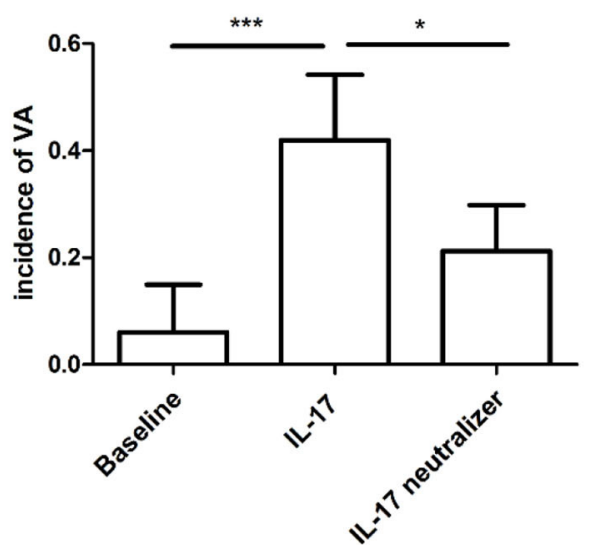

FIGURE 4 | Effects of IL-17 on the maximum slope of APD restitutions and inducibility of ventricular arrhythmia (VA). (A-D) Maximum slope of APD restitutions. (E) IL-17 on VTNF threshold PCL. (F) Inducibility of VA. ${ }^{*} P<0.05$; ${ }^{* * *} P<0.001$. DI, diastolic interval; VA, ventricular arrhythmia; VT/NF, ventricular tachycardia/ventricular fibrillation and other abbreviations as in Figure 2. 
IL-17 had a lower $\mathrm{Ca}_{\mathrm{i}}$ concentration accumulated over the time of the transient compared to baseline. The $\mathrm{Ca}$ decay time in the IL-17 group was prolonged than that in the baseline and IL-17 neutralizer groups $(45.6 \pm 1.6,34.2 \pm 1.2$, and 37.0 $\pm 1.5 \mathrm{~ms}$, respectively, $P<0.05$ ) (Figure 1C). The effects of IL-17 on $\mathrm{APD}_{80}$ and $\mathrm{Ca}_{\mathrm{i}} \mathrm{TD}_{80}$ at $300 \mathrm{~ms}$ PCL are shown in Figure 2. Compared with the baseline, $\mathrm{APD}_{80}$ and $\mathrm{Ca}_{\mathrm{i}} \mathrm{TD}_{80}$ were prolonged in the IL-17 group ( $P<0.05$ at all PCL). $\mathrm{APD}_{80}$ was shorter in the IL-17 neutralizer group $(P<0.05$ at PCL of 350$500 \mathrm{~ms}$ ) than in the IL-17 group (Figure 2A). The IL-17 group had a longer $\mathrm{Ca}_{\mathrm{i}} \mathrm{TD}_{80}$ than the baseline and IL-17 neutralizer groups at all PCL and PCL of 400-500 ms, respectively, $(P<0.05)$ (Figure 2B). No significant difference in $\mathrm{APD}_{80}$ and $\mathrm{Ca}_{\mathrm{i}} \mathrm{TD}_{80}$ was be found between the baseline and IL-17 neutralizer groups $(\mathrm{P}=\mathrm{NS})$. Compared with the baseline, $\mathrm{SD}$ of $\mathrm{APD}_{80}$ and SD of $\mathrm{Ca}_{\mathrm{i}} \mathrm{TD}_{80}$ were prolonged in the IL-17 group $(P<0.05$ at all PCL). SD of $\mathrm{APD}_{80}$ was shorter in the IL-17 neutralizer group $(P<0.05$ at PCL of $300-400 \mathrm{~ms})$ than in the IL-17 group (Figure 2C). The IL-17 group had a longer $\mathrm{SD}$ of $\mathrm{Ca}_{\mathrm{i}} \mathrm{TD}_{80}$ than the baseline and IL-17 neutralizer groups $(P<0.05$ at PCL of 300-400 ms) (Figure 2D). No significant difference in SD of $\mathrm{APD}_{80}$ and $\mathrm{Ca}_{\mathrm{i}} \mathrm{TD}_{80}$ was found between the baseline and IL-17 neutralizer groups $(\mathrm{P}=\mathrm{NS})$. IL-17 group had a decreased CV compared with baseline and IL-17 neutralizer group. Treatment of IL-17 neutralizer increased CV compared to that in IL-17 group (Figure 2E).

\section{Pacing-Induced APD and $\mathrm{Ca}_{\mathrm{i}}$ TD Alternans}

An example of increased alternans of APD and $\mathrm{Ca}_{\mathrm{i}} \mathrm{TD}$ with decreasing PCL is shown in Figure 3A. In the IL-17 group, $\mathrm{Ca}_{\mathrm{i}}$ alternans were induced at $250 \mathrm{~ms}$ PCL, and APD alternans were detected at $200 \mathrm{~ms}$ PCL. In the baseline group, $\mathrm{Ca}_{\mathrm{i}}$ alternans were induced at $160 \mathrm{~ms}$ PCL, whereas APD alternans were not detected. In the IL-17 neutralizer group, significant $\mathrm{Ca}_{\mathrm{i}}$ alternans were induced at $180 \mathrm{~ms}$ PCL, and APD alternans were detected at $160 \mathrm{~ms}$ PCL. The PCL threshold of $\mathrm{Ca}_{\mathrm{i}}$ alternans was greater in the IL-17 group than in the baseline (IL-17 vs. baseline, 223 \pm 25 vs. $178 \pm 11 \mathrm{~ms} ; P<0.001)$ and IL-17 neutralizer groups (IL-17 vs. IL-17 neutralizer, $223 \pm 25$ vs. $192 \pm 9 \mathrm{~ms} ; P=$ 0.013). The PCL threshold of APD alternans was greater in the IL-17 group than in the baseline (IL-17 vs. baseline, $182 \pm 13$ vs. $161 \pm 13 \mathrm{~ms} ; P=0.002$ ) and IL-17 neutralizer groups (IL17 vs. IL-17 neutralizer, $182 \pm 13$ vs. $160 \pm 8 \mathrm{~ms} ; P=0.011$ ) (Figure 3B). No significant difference in the PCL threshold of APD and $\mathrm{Ca}_{\mathrm{i}} \mathrm{TD}$ alternans was observed between the baseline and IL-17 neutralizer groups $(\mathrm{P}=\mathrm{NS})$. The SDA threshold of $\mathrm{Ca}_{\mathrm{i}}$ alternans was greater in the IL-17 group than in the baseline (IL17 vs. baseline, $217 \pm 10.5$ vs. $171 \pm 2.9 \mathrm{~ms} ; P<0.001)$ and IL-17 neutralizer groups (IL-17 vs. IL- 17 neutralizer, $217 \pm 10.5$ vs. 186 $\pm 6.7 \mathrm{~ms} ; P=0.003)$. The SDA threshold of APD alternans was greater in the IL-17 group than in the baseline (IL-17 vs. baseline, $178 \pm 4.8$ vs. $153 \pm 2.1 \mathrm{~ms} ; P<0.001)$ and IL-17 neutralizer groups (IL-17 vs. IL-17 neutralizer, $178 \pm 4.8$ vs. $166 \pm 6.7 \mathrm{~ms}$; $P=0.091$ ) (Figure 3C). IL-17 group had a higher incidence of pacing induced positive coupling of $\mathrm{Ca}_{\mathrm{i}}-\mathrm{Vm}$ alternans compared to baseline (IL-17 vs. baseline, $0.20 \pm 0.04$ vs. $0.03 \pm 0.02 ; P<$ 0.001 ) and IL-17 neutralizer group(IL-17 vs. IL-17 neutralizer, $0.20 \pm 0.04$ vs. $0.03 \pm 0.03 ; P=0.004)$. IL-17 group had a higher incidence of pacing induced negative coupling of $\mathrm{Ca}_{\mathrm{i}}-\mathrm{Vm}$ alternans compared to baseline (IL-17 vs. baseline, $0.40 \pm 0.03$ vs. $0.07 \pm 0.03 ; P<0.001$ ) and IL-17 neutralizer group (IL-17 vs. IL17 neutralizer, $0.40 \pm 0.03$ vs. $0.25 \pm 0.06 ; P=0.04$ ) (Figure 3D). No significant difference in PCL threshold of positive coupling of $\mathrm{Ca}_{\mathrm{i}}-\mathrm{Vm}$ alternans was be found between the baseline and IL17 neutralizer groups. The PCL threshold of negative coupling of $\mathrm{Ca}_{\mathrm{i}}-\mathrm{Vm}$ alternans was greater in the IL-17 group than in the baseline (IL-17 vs. baseline, $227 \pm 10.5$ vs. $176 \pm 4.4 \mathrm{~ms} ; P<$ 0.001 ) and IL-17 neutralizer groups (IL-17 vs. IL-17 neutralizer, $227 \pm 10.5$ vs. $184 \pm 7.5 \mathrm{~ms} ; P=0.001$ ) (Figure 3E).

\section{Effect of IL-17 on the Maximum Slope of APD Restitution Curves and PCL Threshold Triggering Ventricular \\ Tachycardia/Ventricular Fibrillation}

The IL-17 group had higher maximum slopes of APD restitution (APDR) curves than the baseline group $(2.1 \pm 0.8$ vs. $0.7 \pm 0.4$; $P<0.001)$. And, there were significant differences in maximum slopes of APDR curves between the IL-17 and IL-17 neutralizer groups $(2.1 \pm 0.8$ vs. $1.0 \pm 0.2 ; P=0.008)$ (Figures $4 \mathrm{~A}-\mathrm{D}$ ). The PCL threshold triggering ventricular tachycardia/ventricular fibrillation (VT/VF) was higher in the IL-17 group than in the baseline (IL-17 vs. baseline, $170 \pm 20 \mathrm{~ms}$ vs. $130 \pm 10 \mathrm{~ms} ; P=$ 0.01 ) and IL-17 neutralizer groups (IL-17 vs. IL-17 neutralizer, $170 \pm 20$ vs. $143 \pm 5 \mathrm{~ms} ; P=0.05$ ) (Figure 4E). VA inducibility was higher in IL-17 compared with the baseline and IL-17 neutralizer group (Figure 4F).

\section{Effect of IL-17 on VF Dynamics in Normal Ventricles}

Figure 5A shows the p-ECG recordings of VF in the baseline, IL17 and IL-17 neutralizer groups. The DF of VF was decreased from $13.7 \mathrm{~Hz}$ (IL-17 group) to $9.0 \mathrm{~Hz}$ after IL-17 neutralizer treatment (IL-17 neutralizer group) compared with the baseline group $(6.8 \mathrm{~Hz})$. The IL-17 group had a higher DF of VA than that of the baseline group (IL-17 vs. baseline, $12.5 \pm 0.5$ vs. $7.7 \pm 0.7 \mathrm{~Hz} ; P<0.001)$ and IL-17 neutralizer group (IL-17 vs. IL-17 neutralizer, $12.5 \pm 0.5$ vs. $9.0 \pm 0.5 \mathrm{~Hz}$; $P<0.001$ ) (Figure 5B). Phase maps sampled during VF were analyzed for PSs (wavebreaks). Figure 5C shows phase maps with PSs (black arrows) of the baseline, IL-17 and IL17 neutralizer groups in LV. The IL-17 group increased PSs than the baseline group (IL-17 vs. baseline, $0.5 \pm 0.10$ vs. $0.1 \pm 0.01 ; P<0.001$ ) and IL-17 neutralizer group (IL17 vs. L-17 neutralizer, $0.5 \pm 0.10$ vs. $0.1 \pm 0.02 ; P<$ $0.001)$.

\section{The mRNA Expression of Ion Channels in IL-17-Treated Rabbit Hearts}

Using semiquantitative reverse transcription polymerase chain reaction (RT-PCR), we found mRNA levels that the $\mathrm{Na}^{+} / \mathrm{Ca}^{2+}$ exchanger (NCX), phospholamban (PLB), and ryanodine receptor $\mathrm{Ca}^{2+}$ release channel (RyR) were significantly upregulated in the IL-17 group compared with the baseline and IL-17 neutralizer groups. The mRNA level of RyR was significantly reduced in the baseline group compared with 


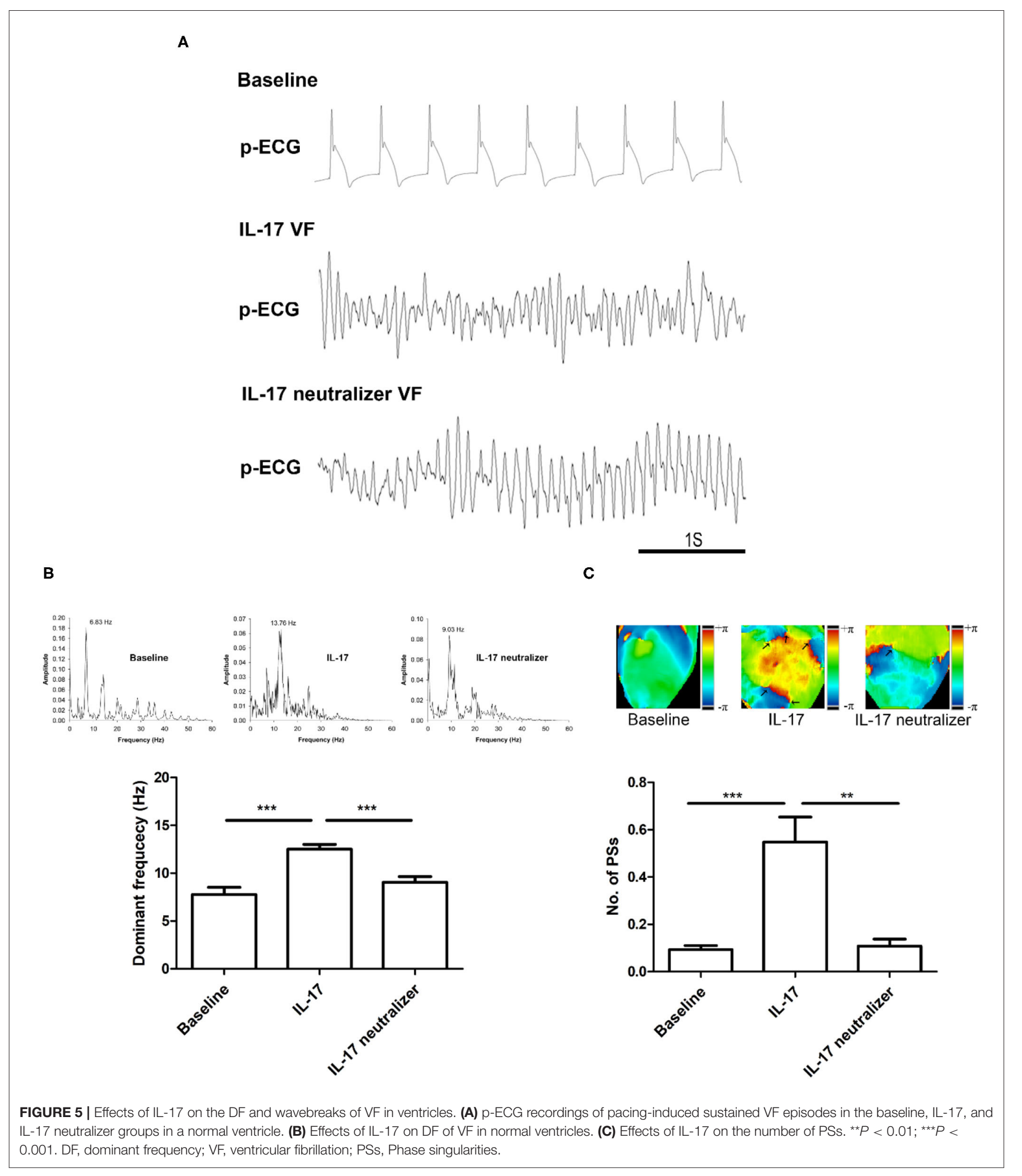

the IL-17 neutralizer group. The subunit of the L-type $\mathrm{Ca}^{2+}$ current $\left(I_{\mathrm{CaL}}\right) \mathrm{Cav1.2}$ and sarcoplasmic reticulum $\mathrm{Ca}^{2+}$-ATPase (SERCA2a) were significantly reduced in the IL-17 group compared with the baseline and IL-17 neutralizer groups. No significant difference in the mRNA levels of NCX, Cav1.2,
SERCA2a, and PLB was found between the baseline and IL-17 neutralizer groups. Furthermore, among the 3 groups, no significant difference in the mRNA levels of the following was observed: the $\alpha 1$-subunit of $\mathrm{Na}$ channel, Nav1.5; the subunit of the inward rectifier potassium current $\left(I_{\mathrm{K} 1}\right)$, Kir2.1; the 


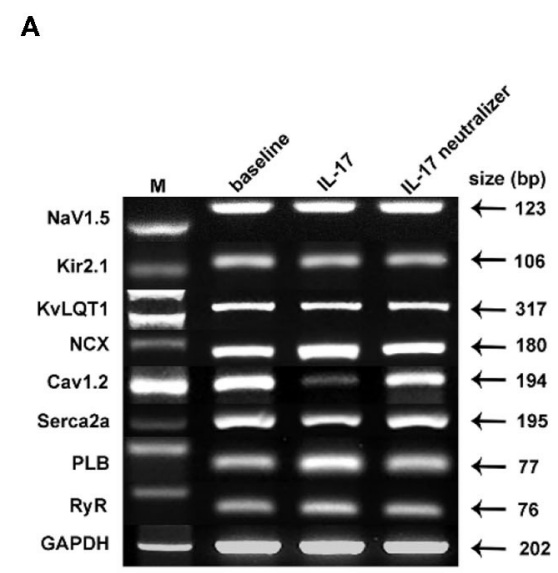

\section{$\mathbf{B}$}
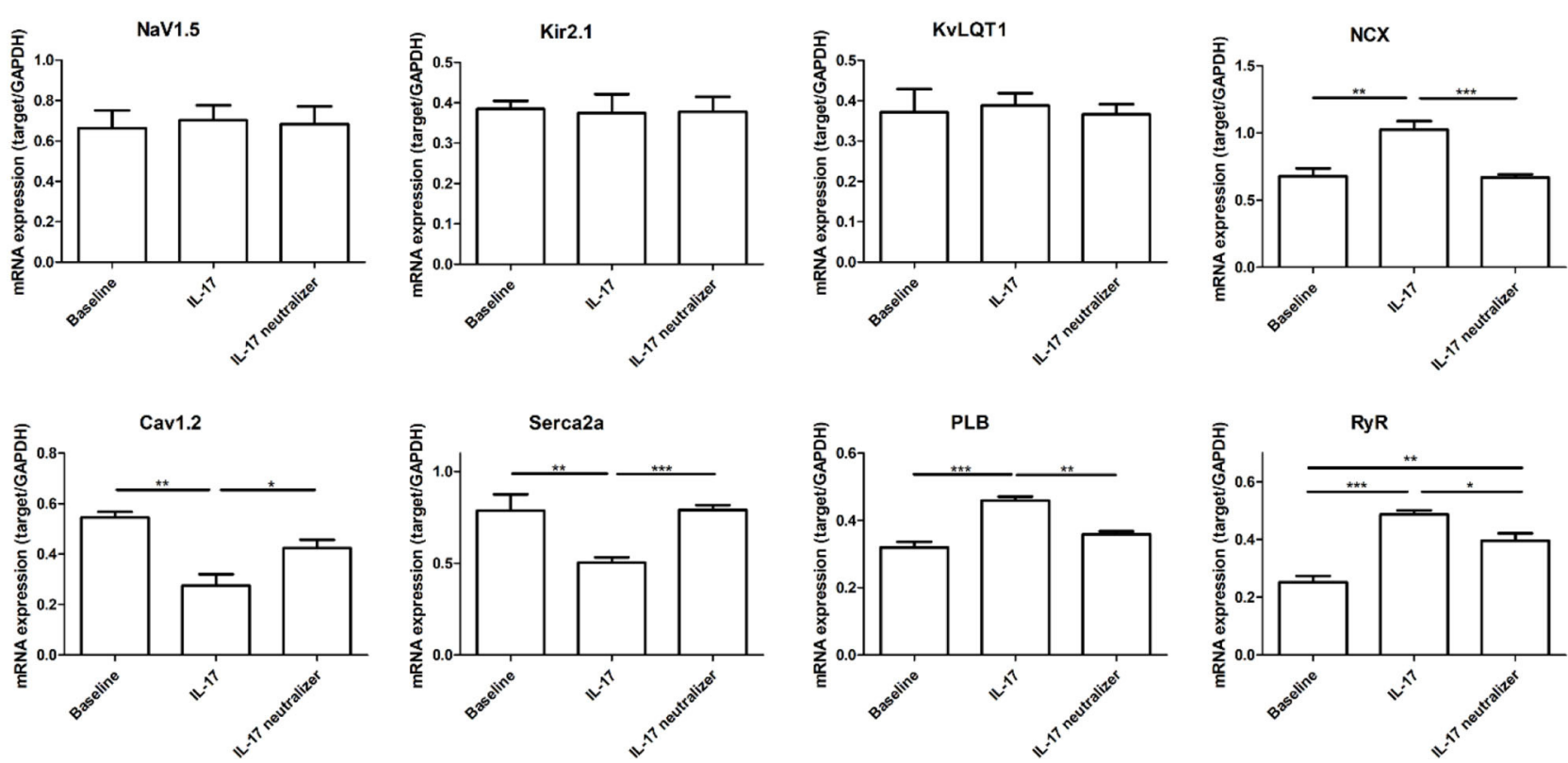

FIGURE 6 | Expressions of various ion channels target in left ventricular. Relative quantities of mRNA levels by semiquantitative RT-PCR were shown among the 3 groups. (A) Shows RT-PCR gels for Nav1.5, Kir2.1, KvLQT1, NCX, Cav1.2, SERCA2a, PLB, and RyR. (B) Demonstrates the relative mRNA expression quantity. Each value represents the mean $\pm \mathrm{SD}$ of 3 or more repeat experiments. ${ }^{\star} P<0.05$; ${ }^{\star \star} P<0.01$; ${ }^{\star \star \star} P<0.001$. KVLQT1, subunit of $I_{\mathrm{Ks}}$; Nav1.5, $\alpha 1$-subunit of Na channel; Cav1.2, subunit of $I_{\mathrm{CaL}}$; NCX, sodium-calcium exchanger; Kir2.1, subunit of IK1; RyR, ryanodine receptor Ca ${ }^{2+}$ release channel; PLB, phospholamban; SERCA2a, sarcoplasmic reticulum $\mathrm{Ca}^{2+}$-ATPase; mRNA, messenger ribonucleic acid; RT-PCR, reverse transcription polymerase chain reaction.

subunit of the slow delayed rectifier current $\left(I_{\mathrm{Ks}}\right)$, KvLQT1 (Figures 6A,B).

\section{DISCUSSION}

\section{IL-17 Modulates Electrophysiology of LV}

Increased proinflammatory cytokine levels are associated with HF, hypertension, arrhythmogenic RV cardiomyopathy, and myocardial ischemia $(1,15,16)$. In several case-controlled studies, increased levels of inflammatory markers, such as CRP, IL-6, IL-8, and TNF, and elevated neutrophil and lymphocyte ratios have been reported in patients with arrhythmia compared with those in patients with sinus rhythm (17). The inflammation process enhanced by $\mathrm{HF}$ is associated with the alteration of ionic currents and the $\mathrm{Ca}_{\mathrm{i}}$ transient, which predisposes to VA (15). Electrical remodeling prolonged APD and steepened the maximum slope of APDR, which promotes dynamical instability, wavebreaks, and VF $(4,18)$. Mediators of the inflammatory response can alter electrophysiology and structural substrates, thereby promoting arrhythmia susceptibility. The proinflammatory cytokine such as TNF- $\alpha$ and IL- $1 \beta$ can decrease the SERCA2 expression, which prolongs $\mathrm{Ca}_{\mathrm{i}} \mathrm{TD}$ and APD (19). The participation of different inflammation-related cytokines and chemokines has been proposed in the pathophysiology of arrhythmia $(4,19)$. We previously reported treatment IL17 directly induced VA in a dose-dependent manner (4). In 


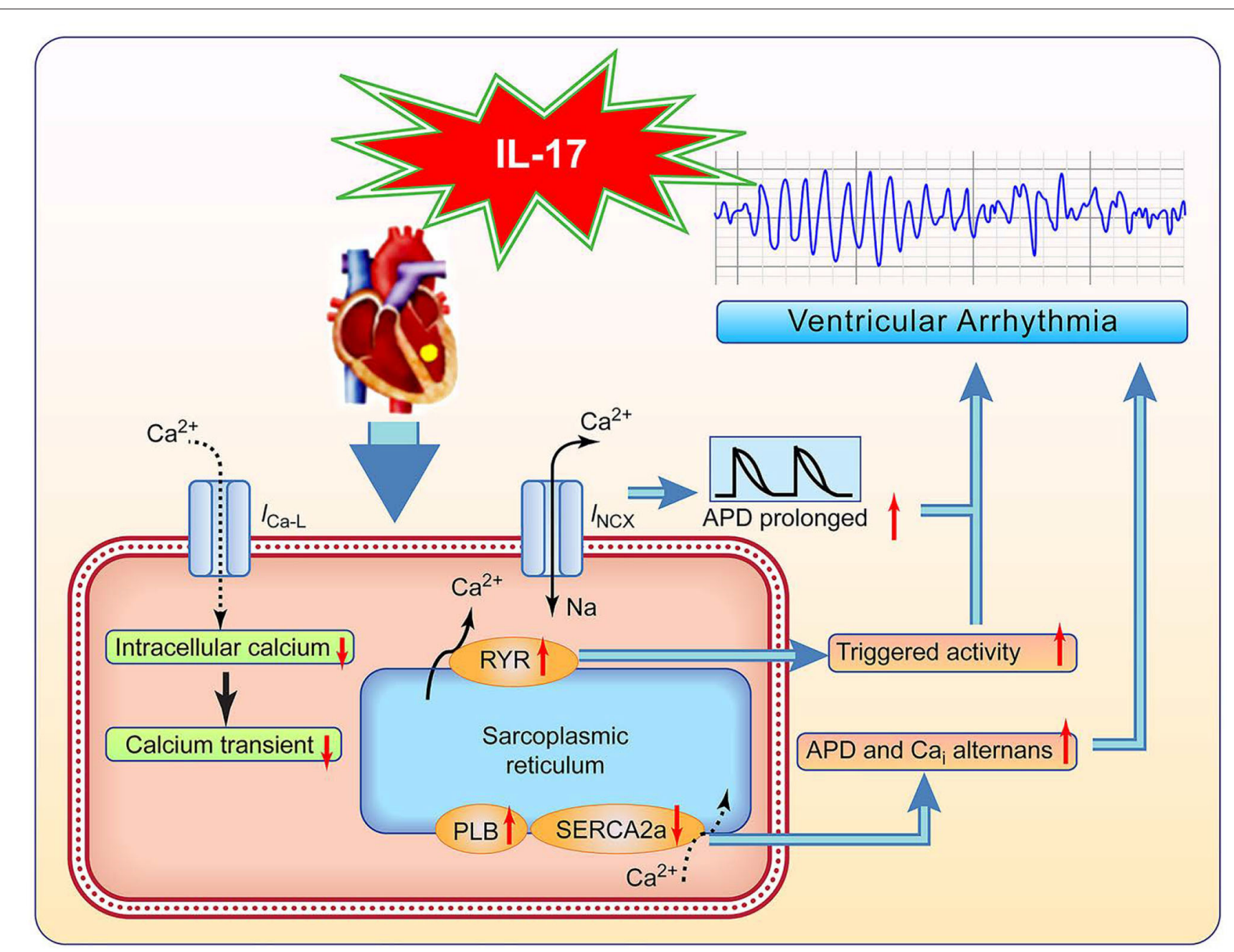

FIGURE 7 | Proposed pathway of IL-17 effects on ventricular arrhythmia (VA). ICaL, L-type calcium current; $/ \mathrm{NCX}, \mathrm{Na}{ }^{+}-\mathrm{Ca}{ }^{2+}$ exchanger current; and other abbreviations as in Figures 2, 3, 6.

agreement with previous studies, our present study showed that IL-17 prolonged APD and $\mathrm{Ca}_{\mathrm{i}} \mathrm{TD}$ and steepened the maximum slope of APDR, which may result in VA.

\section{Effects of IL-17 on Electrical Alternans}

$\mathrm{APD}$ and $\mathrm{Ca}_{\mathrm{i}}$ alternans are related with arrhythmogenesis, where SDA between myocytes amplify repolarization gradients to produce conduction block and reentrant excitation (20). In our present study, IL-17 enhanced the $\mathrm{Ca}_{\mathrm{i}}$ and $\mathrm{APD}$ alternans and decreased $\mathrm{Ca}_{\mathrm{i}}$ transient, which may increase VA susceptibility. In the $\mathrm{HF}$ model, a decrease in $\mathrm{Ca}_{\mathrm{i}}$ transient amplitude and contractile dysfunction can be produced by $\mathrm{Ca}^{2+}$ leak through the sarcoplasmic reticulum (SR) $\mathrm{Ca}^{2+}$ channel RyR and/or reduced activity of SERCA2a (21). TNF- $\alpha$ causes abnormal $\mathrm{Ca}_{\mathrm{i}}$ handling and arrhythmogenicity in pulmonary vein cardiomyocytes, and it can reduce the mRNA expression of SERCA2a by enhancing methylation in the promoter region (22). IL- $1 \beta$ significantly reduces the contractility of cardiomyocytes and the amplitude and speed of $\mathrm{Ca}_{\mathrm{i}}$ transients, and it encourage
SR $\mathrm{Ca}^{2+}$ leak and spontaneous arrhythmic activity when they interact with other inflammatory cytokines (19). Two major mechanisms for the growth of SDA have been proposed: voltageand $\mathrm{Ca}^{2+}$-driven mechanisms (23). The first mechanism was purely Vm potential-driven, which was coupled through the dynamic interaction between the APDR curve and CV restitution curve; however, the $\mathrm{Ca}^{2+}$-driven mechanism was considered to be more complex, with discordant alternans produced by instabilities in $\mathrm{Ca}_{\mathrm{i}}$ cycling that impact $\mathrm{APD}$ through $\mathrm{Ca}_{\mathrm{i}}-\mathrm{Vm}$ coupling (24). $\mathrm{Ca}_{\mathrm{i}}-\mathrm{Vm}$ coupling depended on a dynamic balance between the influx through $I_{\mathrm{CaL}}$ and extrusion through the NCX current $\left(I_{\mathrm{NCX}}\right)$ (23). If the effect of $I_{\mathrm{NCX}}$ is dominant, positive $\mathrm{Ca}_{i}-\mathrm{Vm}$ coupling occurs, where increased $\mathrm{Ca}_{\mathrm{i}}$ induces prolonged APD by enhancing $\mathrm{Ca}^{2+}$ extrusion through $I_{\mathrm{NCX}}$. If Ca-dependent inactivation of $I_{\mathrm{CaL}}$ dominates, a large $\mathrm{Ca}_{\mathrm{i}}$ transient will rapidly inactivate $I_{\mathrm{CaL}}$ and tend to shorten APD (24). Electrical alternans have previously been attributed to the disturbances in $\mathrm{Ca}_{\mathrm{i}}$ signaling, and APD alternans are considered to be a secondary consequence (24). 


\section{IL-17 Modulates Calcium Handling}

In our study, mRNA levels of Cav1.2 and SEARCA2a were downregulated in the IL-17 group, and IL-17 neutralizer treatment reversed these changes. The increase in mRNA expression of NCX during HF was found to be associated with imperfect SERCA2a function. Upregulated NCX activity leads to APD prolongation and repolarization instability during HF (25). In the present study, NCX was upregulated in the IL-17 group, and IL-17 neutralizer treatment reversed the change in expression of NCX caused by IL-17. A previous study showed that PLB ablation in TNF1.6 mice (TKO mice) improved contractile function and $\mathrm{Ca}_{\mathrm{i}}$ transients in isolated cardiomyocytes (26). TNF- $\alpha$-induced caspase- 8 activation results in the leakage of RyR2 channels that promote cardiac remodeling after myocardial ischemia/reperfusion (27). Increased RyR sensitivity and reduced $I_{\mathrm{K} 1}$ contributes to sustained focal arrhythmia in rabbits (28). In agreement with previous reports, our present study demonstrated that the mRNA expressions of PLB and RyR were upregulated in the IL-17 group, and IL17 neutralizer treatment downregulated these expressions to the baseline, suggesting that abnormal $\mathrm{Ca}_{\mathrm{i}}$ handling caused by IL-17 can result in VA. In our previous study, the expression of IL17 via activating MAPK pathway might play an important role in generating VA in ischemic HF. Moreover, our present study showed that IL-17 enhanced $\mathrm{Ca}_{\mathrm{i}}$ TD and APD alternans through the disturbances in calcium handling, which may increase VA susceptibility in normal substrate.

\section{Possible Mechanism and Clinical Implication}

We propose a possible mechanism for IL-17-induced VA (Figure 7). IL-17 administration decreased the mRNA expression of Cav1.2 and enhanced that of PLB, resulting in decreased $\mathrm{Ca}_{\mathrm{i}}$ and $\mathrm{Ca}_{\mathrm{i}}$ transient. IL-17 administration increased NCX activity contributing to APD prolongation, repolarization instability, and increased RyR sensitivity. Decreased SERCA2a levels may result in susceptibility to APD and $\mathrm{Ca}_{\mathrm{i}}$ alternans with IL-17 administration. Therefore, IL-17 causes electrical and structural remodeling, resulting in VA. In ischemic HF patients, IL-17 levels may function as a biomarker for monitoring the incidence of VA. A recent study demonstrated that anti-inflammatory therapy targeting IL-1 $\beta$ suppression decreased cardiovascular events in myocardial ischemia patients (16). IL-17 suppression may provide a new therapy to prevent VA in ischemic HF patients.

\section{Limitation}

First, small sample size may cause an insignificant result of IL 17-neutralizer on calcium transients compared to those on baseline. With more statistical power a significant result might be obtained. It is also possible that IL-17 might cause a reduction in $\mathrm{Ca}_{\mathrm{i}}$ transients through multiple mechanisms rather than the IL-17 receptor alone. Both IL-17 and IL-17 neutralizer can not be washed out. There was no time control in this study. We only examined mRNA expression of ionic channels and calcium handling. It is difficult to directly link the gene expression and functional data. The RNA transcriptions of calcium handling proteins may not fully explain the results observed during measurements of calcium transients. Further study is needed to clarify this issue. Cytochalasin-D has been reported to affect repolarization/conduction patterns and $\mathrm{Ca}_{\mathrm{i}}$. These effects might interfere with the current results in our rabbit model. A $2 \mathrm{~ms}$ frame rate might not be optimal for determining activation/rise time characteristics, and a higher frame rate is optimal.

\section{CONCLUSIONS}

Enhanced electrical alternans and abnormal $\mathrm{Ca}_{\mathrm{i}}$ handling caused by IL-17 can increase susceptibility of VA in normal rabbit heart. Suppression of IL-17 may reverse the adverse effect, providing a potential treatment for VA.

\section{DATA AVAILABILITY STATEMENT}

The original contributions presented in the study are included in the article/Supplementary Material, further inquiries can be directed to the corresponding author/s.

\section{ETHICS STATEMENT}

The animal study was reviewed and approved by Institutional Animal Care and Use Committee of Taipei Veterans General Hospital.

\section{AUTHOR CONTRIBUTIONS}

Y-NT: conceptualization, investigation, methodology, and writing-original draft. Y-WH: conceptualization, validation, and data curation. S-FL: software and resources. Y-HC and Y-CH: formal analysis. W-HT, H-YL, and T-JW: resources. A-SL: methodology. Y-TH: data curation. T-FC and SH: funding acquisition. S-LC: resources, funding acquisition, project administration, and supervision. S-AC: writing-review and editing, supervision, and funding acquisition. All authors contributed to the article and approved the submitted version.

\section{FUNDING}

This study was supported by Ministry of Science and Technology, Taiwan (Grant no. 106-2314-B-010-035-MY3), Taipei Veterans General Hospital (Grant nos. V107C-041, V108C-055, and VGHUST107-G1-7-1), Foundation for the Development of Internal Medicine in Okinawa (Grant nos. 31-02-001 and 31-02002), and SZU-YUAN Research Foundation of Internal Medicine (Grant no. 108010).

\section{ACKNOWLEDGMENTS}

The authors would like to thank Enago (www.enago.tw) for the English language review.

\section{SUPPLEMENTARY MATERIAL}

The Supplementary Material for this article can be found online at: https://www.frontiersin.org/articles/10.3389/fcvm. 2021.623510/full\#supplementary-material 


\section{REFERENCES}

1. Bozkurt B, Mann DL, Deswal A. Biomarkers of inflammation in heart failure. Heart Fail Rev. (2010) 15:331-41. doi: 10.1007/s10741-009-9140-3

2. Gaffen SL. Structure and signalling in the IL-17 receptor family. Nat Rev Immunol. (2009) 9:556-67. doi: 10.1038/nri2586

3. Montalbano M, Riccobono L, Siena L, Chiappara G, Di Sano C, Anzalone G, et al. Cigarette smoke affects IL-17A, IL-17F and IL-17 receptor expression in the lung tissue: Ex vivo and in vitro studies. Cytokine. (2015) 76:391402. doi: 10.1016/j.cyto.2015.07.013

4. Chang SL, Hsiao YW, Tsai YN, Lin SF, Liu SH, Lin YJ, et al. Interleukin-17 enhances cardiac ventricular remodeling via activating MAPK pathway in ischemic heart failure. J Mol Cell Cardiol. (2018) 122:6979. doi: 10.1016/j.yjmcc.2018.08.005

5. Valente J, Yoshida T, Gardner JD, Somanna N, Delafontaine P, Chandrasekar B. Interleukin-17A stimulates cardiac fibroblast proliferation and migration via negative regulation of the dual-specificity phosphatase MKP-1/DUSP-1. Cell Signal. (2012) 24:560-8. doi: 10.1016/j.cellsig.2011.10.010

6. Chan YH, Tsai WC, Ko JS, Yin D, Chang PC, Rubart M, et al. Small-conductance calcium-activated potassium current is activated during hypokalemia and masks short-term cardiac memory induced by ventricular pacing. Circulation. (2015) 132:1377-86. doi: 10.1161/CIRCULATIONAHA.114.015125

7. Hsieh YC, Chang PC, Hsueh CH, Lee YS, Shen C, Weiss JN, et al. Apamin-sensitive potassium current modulates action potential duration restitution and arrhythmogenesis of failing rabbit ventricles. Circ Arrhythm Electrophysiol. (2013) 6:410-8. doi: 10.1161/CIRCEP.111.000152

8. Yin $\mathrm{D}$, Chen $\mathrm{M}$, Yang $\mathrm{N}, \mathrm{Wu} \mathrm{AZ}, \mathrm{Xu} \mathrm{D}$, Tsai WC, et al. Role of apamin-sensitive small conductance calcium-activated potassium currents in long-term cardiac memory in rabbits. Heart Rhythm. (2018) 15:7619. doi: 10.1016/j.hrthm.2018.01.016

9. Richter F, Natura G, Ebbinghaus M, von Banchet GS, Hensellek S, Konig C, et al. Interleukin-17 sensitizes joint nociceptors to mechanical stimuli and contributes to arthritic pain through neuronal interleukin-17 receptors in rodents. Arthritis Rheum. (2012) 64:4125-34. doi: 10.1002/art.37695

10. Song X, Qian Y. The activation and regulation of IL-17 receptor mediated signaling. Cytokine. (2013) 62:175-82. doi: 10.1016/j.cyto.2013.03.014

11. Tsai CT, Chiang FT, Tseng CD, Yu CC, Wang YC, Lai LP, et al. Mechanical stretch of atrial myocyte monolayer decreases sarcoplasmic reticulum calcium adenosine triphosphatase expression and increases susceptibility to repolarization alternans. J Am Coll Cardiol. (2011) 58:210615. doi: 10.1016/j.jacc.2011.07.039

12. Wu TJ, Lin SF, Weiss JN, Ting CT, Chen PS. Two types of ventricular fibrillation in isolated rabbit hearts: importance of excitability and action potential duration restitution. Circulation. (2002) 106:1859-66. doi: 10.1161/01.CIR.0000031334.49170.FB

13. Hsieh YC, Lin JC, Hung CY, Li CH, Lin SF, Yeh HI, et al. Gap junction modifier rotigaptide decreases the susceptibility to ventricular arrhythmia by enhancing conduction velocity and suppressing discordant alternans during therapeutic hypothermia in isolated rabbit hearts. Heart Rhythm. (2016) 13:251-61. doi: 10.1016/j.hrthm.2015.07.023

14. Weiss JN, Nivala M, Garfinkel A, Qu Z. Alternans and arrhythmias: from cell to heart. Circ Res. (2011) 108:98-112. doi: 10.1161/CIRCRESAHA.110. 223586

15. Nakamura R, Egashira K, Machida Y, Hayashidani S, Takeya M, Utsumi $\mathrm{H}$, et al. Probucol attenuates left ventricular dysfunction and remodeling in tachycardia-induced heart failure: roles of oxidative stress and inflammation. Circulation. (2002) 106:362-7. doi: 10.1161/01.CIR.0000021430.04195.51
16. Ridker PM, Everett BM, Thuren T, MacFadyen J, Chang WH, Ballantyne C, et al. Antiinflammatory therapy with canakinumab for atherosclerotic disease. $N$ Engl J Med. (2017) 377:1119-31. doi: 10.1056/NEJMoa1707914

17. Marcus GM, Smith LM, Glidden DV, Wilson E, McCabe JM, Whiteman D, et al. Markers of inflammation before and after curative ablation of atrial flutter. Heart Rhythm. (2008) 5:215-21. doi: 10.1016/j.hrthm.2007.10.007

18. Weiss JN, Qu Z, Chen PS, Lin S, Karagueuzian HS, Hayashi H, et al. The dynamics of cardiac fibrillation. Circulation. (2005) 112:123240. doi: 10.1161/CIRCULATIONAHA.104.529545

19. Duncan DJ, Yang Z, Hopkins PM, Steele D, Harrison SM. TNF-alpha and IL1beta increase $\mathrm{Ca}^{+}$leak from the sarcoplasmic reticulum and susceptibility to arrhythmia in rat ventricular myocytes. Cell Calcium. (2010) 47:37886. doi: 10.1016/j.ceca.2010.02.002

20. Pastore JM, Girouard SD, Laurita KR, Akar FG, Rosenbaum DS. Mechanism linking T-wave alternans to the genesis of cardiac fibrillation. Circulation. (1999) 99:1385-94. doi: 10.1161/01.CIR.99.10.1385

21. Sankaranarayanan R, Li Y, Greensmith DJ, Eisner DA, Venetucci L. Biphasic decay of the Ca transient results from increased sarcoplasmic reticulum $\mathrm{Ca}$ leak. J Physiol. (2016) 594:611-23. doi: 10.1113/JP271473

22. Kao YH, Chen YC, Cheng CC, Lee TI, Chen YJ, Chen SA. Tumor necrosis factor-alpha decreases sarcoplasmic reticulum $\mathrm{Ca} 2{ }^{+}$-ATPase expressions via the promoter methylation in cardiomyocytes. Crit Care Med. (2010) 38:21722. doi: 10.1097/CCM.0b013e3181b4a854

23. Saitoh H, Bailey JC, Surawicz B. Action potential duration alternans in dog Purkinje and ventricular muscle fibers. Further evidence in support of two different mechanisms. Circulation. (1989) 80:1421-31. doi: 10.1161/01.CIR.80.5.1421

24. Weiss JN, Karma A, Shiferaw Y, Chen PS, Garfinkel A, Qu Z. From pulsus to pulseless: the saga of cardiac alternans. Circ Res. (2006) 98:124453. doi: 10.1161/01.RES.0000224540.97431.f0

25. Arai M, Alpert NR, MacLennan DH, Barton P, Periasamy M. Alterations in sarcoplasmic reticulum gene expression in human heart failure. A possible mechanism for alterations in systolic and diastolic properties of the failing myocardium. Circ Res. (1993) 72:463-9. doi: 10.1161/01.RES.72.2.463

26. Janczewski M, Zahid M, Lemster BH, Frye CS, Gibson G, Higuchi Y, et al. Phospholamban gene ablation improves calcium transients but not cardiac function in a heart failure model. Cardiovasc Res. (2004) 62:46880. doi: 10.1016/j.cardiores.2004.02.006

27. Fauconnier J, Meli AC, Thireau J, Roberge S, Shan J, Sassi Y, et al. Ryanodine receptor leak mediated by caspase- 8 activation leads to left ventricular injury after myocardial ischemia-reperfusion. Proc Natl Acad Sci USA. (2011) 108:13258-63. doi: 10.1073/pnas.1100286108

28. Myles RC, Wang L, Bers DM, Ripplinger CM. Decreased inward rectifying $\mathrm{K}^{+}$ current and increased ryanodine receptor sensitivity synergistically contribute to sustained focal arrhythmia in the intact rabbit heart. J Physiol. (2015) 593:1479-93. doi: 10.1113/jphysiol.2014.279638

Conflict of Interest: The authors declare that the research was conducted in the absence of any commercial or financial relationships that could be construed as a potential conflict of interest.

Copyright (C) 2021 Tsai, Hsiao, Lin, Chan, Hsieh, Tang, Lee, Huang, Li, Chao, Higa, $W u$, Chang and Chen. This is an open-access article distributed under the terms of the Creative Commons Attribution License (CC BY). The use, distribution or reproduction in other forums is permitted, provided the original author(s) and the copyright owner(s) are credited and that the original publication in this journal is cited, in accordance with accepted academic practice. No use, distribution or reproduction is permitted which does not comply with these terms. 